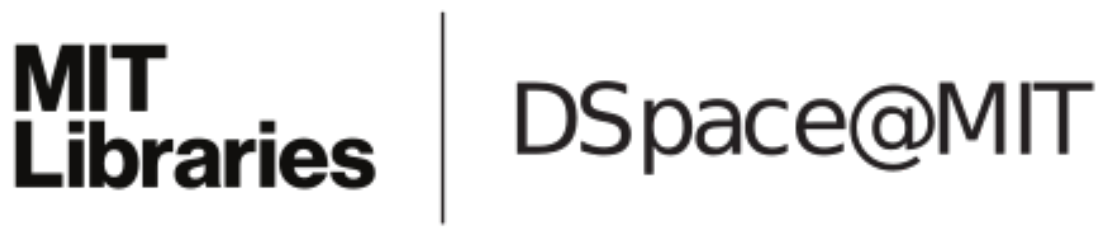

\author{
MIT Open Access Articles
}

Sensing and inactivation of Bacillus anthracis Sterne by polymer-bromine complexes

The MIT Faculty has made this article openly available. Please share how this access benefits you. Your story matters.

Citation: D’Angelo, Paola A., Lev Bromberg, T. Alan Hatton, and Eugene Wilusz. “Sensing and Inactivation of Bacillus Anthracis Sterne by Polymer-bromine Complexes." Applied Microbiology and Biotechnology 100, no. 15 (April 18, 2016): 6847-6857.

As Published: http://dx.doi.org/10.1007/s00253-016-7507-7

Publisher: Springer Berlin Heidelberg

Persistent URL: http://hdl.handle.net/1721.1/104362

Version: Author's final manuscript: final author's manuscript post peer review, without publisher's formatting or copy editing

Terms of use: Creative Commons Attribution-Noncommercial-Share Alike 


\title{
Sensing and inactivation of Bacillus anthracis Sterne by polymer-bromine complexes
}

\author{
Paola A. D'Angelo ${ }^{1} \cdot$ Lev Bromberg $^{2} \cdot$ T. Alan Hatton ${ }^{2}$ - Eugene Wilusz ${ }^{1}$
}

Received: 18 February 2016/Revised: 22 March 2016/Accepted: 25 March 2016/Published online: 18 April 2016

(C) Springer-Verlag Berlin Heidelberg (outside the USA) 2016

\begin{abstract}
We report on the performance of brominated poly( $N$-vinylpyrrolidone) (PVP-Br), brominated poly(ethylene glycol) (PEG-Br), and brominated poly(allylamine-co-4aminopyridine) (PAAm-APy-Br) for their ability to decontaminate Bacillus anthracis Sterne spores in solution while also allowing for the sensing of the spores. The polymers were brominated by bromine using carbon tetrachloride or potassium tribromide as solvents, with bromine loadings ranging from 1.6 to $4.2 \mathrm{mEq} / \mathrm{g}$ of polymer. B. anthracis Sterne spores were exposed to increasing concentrations of brominated polymers for $5 \mathrm{~min}$, while the kinetics of the sporicidal activity was assessed. All brominated polymers demonstrated spore $\log$-kills of 8 within $5 \mathrm{~min}$ of exposure at $12 \mathrm{mg} / \mathrm{mL}$ aqueous polymer concentration. Sensing of spores was accomplished by measuring the release of dipicolinic acid (DPA) from the spore using time-resolved fluorescence. Parent, nonbrominated polymers did not cause any release of DPA and the spores remained viable. In contrast, spores exposed to the brominated polymers were inactivated and the release of DPA was observed within minutes of exposure. Also, this release of DPA continued for a long time after spore inactivation as in a controlled release process. The DPA release was more pronounced for spores exposed to brominated PVP and brominated PEG-8000 compared to brominated PAAm-APy and brominated PEG-400. Using time-resolved fluorescence, we
\end{abstract}

Paola A. D'Angelo

paola.a.dangelo.civ@mail.mil

$1 \quad$ U.S. Army Natick Soldier Research, Development, and Engineering Center, Warfighter Directorate, 15 General Greene Avenue, Natick, MA 01760, USA

2 Department of Chemical Engineering, Massachusetts Institute of Technology, Cambridge, MA 02139, USA detected as low as 2500 B. anthracis spores, with PEG-8000 being more sensitive to low spore numbers. Our results suggest that the brominated polymers may be used effectively as decontamination agents against bacterial spores while also providing the sensing capability.

Keywords Spores - Anthrax decontamination - DPA release from inactivated anthrax $\cdot$ Brominated polymer decontaminants $\cdot$ Sensing anthrax by DPA release

\section{Introduction}

The threat of biological weapons on the battlefield or in terrorist attacks demands the urgent development of sensing and decontamination methods to counter them. Bacterial spores of the genus Bacillus have been used as bioweapons since these organisms are capable of withstanding wet and dry heat, UV and $\gamma$-radiation, desiccation, and extremes of $\mathrm{pH}$ and toxic chemicals as well as predation by other microorganisms that would otherwise kill vegetative bacteria (Mallozzi et al. 2008; Setlow 2007). Bacillus anthracis, the microorganism that causes anthrax, is of particular interest since it is capable of causing high morbidity and mortality and a disease that may be difficult to diagnose and treat (Oncu et al. 2003).

The ability of $B$. anthracis spores to resist chemical or environmental insults is due to their highly organized surface structure that protects the spore against exogenous chemicals. In $B$. anthracis spores, the genetic material in the spore core is protected by multiple layers, an inner membrane that surrounds the spore core, a germ cell wall, an outer spore membrane that surrounds the cortex, a spore coat, and, finally, an outer layer known as exosporium (Fig. 1) (Zaman et al. 2005). Studies agree that most spore coats are composed of proteins as well as low amounts of carbohydrate, lipids, and 


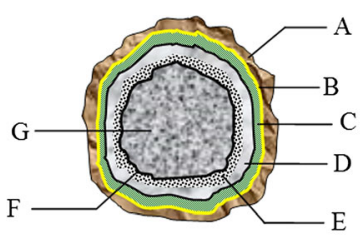

Sporulated

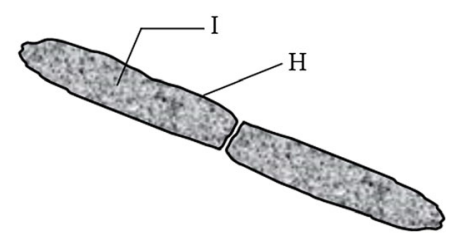

Vegetative
Fig. 1 Schematic representation of $B$. anthracis in their sporulated and germinated states. $A$ exosporium, $B$ spore coat, $C$ outer spore membrane, $D$ spore cortex, $E$ germ cell wall, $F$ inner spore membrane, $G$ spore core, $H$ cell wall, $I$ cell cytoplasm

phosphorus compounds (Driks 1999). Some coat proteins have been found to be highly cross-linked resulting in dense coat layers that can be up to $130 \mathrm{~nm}$ thick, providing a barrier where decontaminating agents cannot penetrate and kill the spore (Henriques and Moran 2000).

In their sporulated form, B. anthracis are metabolically dormant; however, in the presence of nutrients, germinant receptors located on the spore inner membrane get activated initiating a cascade of events that lead to the germination and outgrowth of virulent vegetative bacteria (Foster and Johnstone 1990; Setlow 2003). During germination, release of dipicolinic acid (DPA), loss of spore refractility, loss of heat resistance, hydration of the spore core, and metabolic activity recommences and expression of toxins take place (Setlow 2003). While germination turns $B$. anthracis into an active virulent organism, germinated and vegetative $B$. anthracis are devoid of their protective coat making them susceptible to common disinfectants (Setlow 2003). Because of this susceptibility, current decontamination techniques are more effective on vegetative $B$. anthracis. Development of compounds that can rapidly sense and eradicate $B$. anthracis in their sporulated form is therefore needed.

Current strategies to detect $B$. anthracis spores include detection of events that occur during spore germination (Leuschner et al. 2000; Titball and Manchee 1987; Cheung et al. 1999). Germination of B. anthracis spores is usually detected by procedures where alterations in spore refractility, heat resistance, stainability, and release of DPA are measured (Welkos et al. 2004; Setlow 2003). Since early detection of $B$. anthracis is necessary to avoid dissipation of the pathogen, prevention, and onset of infection, compounds that can detect and simultaneously kill $B$. anthracis spores are needed.

Halogen oxidants have been used to kill a variety of microorganisms. Bleach, chlorine dioxide, ethylene oxide, hydrogen peroxide, and vaporized hydrogen peroxide, among others, were oxidants used in federal decontamination responses following the bioterrorism attacks in 2001 (Hilgren et al. 2007). In a previous study, solutions of sodium hypochlorite were tested against Bacillus subtilis spores and a concentration of $50 \mathrm{ppm}$ available chlorine was needed to obtain a $\sim 2.5$ log-kill in $\sim 18 \mathrm{~min}$ (Williams and Russell 1991). Solutions of sodium dichloroisocyanurate were also tested but a 50 ppm available concentration resulted in a $3 \log$ kill after $45 \mathrm{~min}$ of spore contact with the halogen. While results with halogens as the killing agent of spores are encouraging, faster acting sporicides are needed to decontaminate bioweapons, such as $B$. anthracis, effectively.

In the present work, we set out to design polymeric sporicides since polymers are non-volatile and their functionalities can be varied and controlled through available techniques resulting in bioactive surfaces that are stable under different environments (Lenoir et al. 2006; Tiller et al. 2001; Tiller et al. 2002; Lin et al. 2002). Conjugated polyelectrolytes (CPs) modified with light-absorbing fluorescent molecules can be effective sporicides when exposed to visible light due to the photosensitization effects of the polyelectrolyte that coats the spores ( $\mathrm{Lu}$ et al. 2005). In addition, CPs modified with light quenchers can serve as biosensors since the polymer anchored on the spore can exhibit excited-state superquenching. We believe that halogen-polymer complexes, either neutral or cationic, while being easier to prepare than CPs, can act as both sporicides and sensors. Polymer-bound halogens, and especially Nhalamines (compounds containing N-halogen bond), have been investigated as bactericides as well as oxidizing agents for various toxicants such as pesticides and hydrazines (Amitai et al. 2010; Bromberg et al. 2014). Herein, we addressed a question of whether it is possible to apply a simple complex between an active halogen and an available neutral or cationic polymer to inactivate $B$. anthracis spores in solution. The polymeric species could then be engineered into components of fabrics, protective garments, filters, and other articles. Albeit chlorine- and iodine-containing N-halamine polymers have been widely utilized as antiseptics and disinfectants, considerably less is known about brominecontaining polymers (McLennan et al. 2009; Coulliette et al. 2010).

We chose commercially available, water-soluble and benign polymers such as poly(ethylene glycol) (PEG), polyvinylpyrrolidone (PVP), and polyallylamine (PAAm) as the bromine complexants. Since our concomitant studies demonstrated that PAAm modified with a nucleophilic cationic species, 4-aminopyridine, can efficiently degrade nerve agents (Bromberg et al. 2014), we utilized that modified PAAm to complex with bromine as well, with a potential of gaining a polymeric species with a broad range of applicability in protective fabrics. We also examined if bromine compounds can be used for spore detection, simultaneous with spore inactivation, by monitoring release of DPA from $B$. anthracis after treatment with brominated polymers. 


\section{Materials and methods}

\section{Materials}

Dipicolinic acid (DPA, $99 \%$ ), terbium chloride hexahydrate $(99.9 \%)$, tryptic soy agar, tryptic soy broth, beef extract, peptone, iron sulfate hydrate ( $>99 \%$ ), magnesium sulfate (99\%), manganese chloride tetrahydrate (99\%), calcium nitrate tetrahydrate ( $\geq 99 \%$ ), potassium chloride (99\%), poly(ethylene glycol) (PEG-400, number average molecular weight $M_{\mathrm{n}}$ of 400 and PEG-8000, $M_{\mathrm{n}}$ of 8000 ), potassium bromide (99\%), polyallylamine hydrochloride (PAAm $\mathrm{HCl}$, average molecular weight $\left.M_{\mathrm{w}} 900 \mathrm{kDa}\right)$, polyvinylpyrrolidone (PVP, $M_{\mathrm{w}}$ $1.3 \mathrm{MDa}), 4$-pyridinecarbonitrile (98\%), acrylamide (99 \%), bromine $(\geq 99.5 \%)$ were all obtained from Sigma-Aldrich Chemical Co. All other reagents, solvents, and gases were obtained from commercial sources and were of the highest purity available. Prior to the use, PAAm $\mathrm{HCl}$ was converted to PAAm by neutralization of its $5 \mathrm{wt} \%$ aqueous solution by $2 \mathrm{M} \mathrm{NaOH}$ followed by the polymer dialysis against deionized water (MWCO, 12-13 kDa) and lyophilization. Other polymers were used as received.

B. anthracis Sterne $34 \mathrm{~F} 2\left(\mathrm{pXO}^{+}{ }^{+} \mathrm{pXO}^{-}\right.$; referred to hereafter as $B$. anthracis Sterne) was kindly provided by the Edgewood Chemical Biological Center (ECBC), Edgewood, Maryland.

\section{Spore preparation}

B. anthracis Sterne spores were streaked onto tryptic soy agar (TSA) and incubated at $37{ }^{\circ} \mathrm{C}$ overnight. A $50-\mathrm{mL}$ solution of tryptic soy broth was inoculated using a colony from the freshly grown spores on the agar plate. The solution was incubated at $37{ }^{\circ} \mathrm{C}$ with agitation at $200 \mathrm{RPM}$ for $5 \mathrm{~h}$. After incubation, $500 \mu \mathrm{L}$ of incubated spore solution was placed in $2.5 \mathrm{~L}$ of sporulation media ( $3 \mathrm{~g}$ beef extract, $5 \mathrm{~g}$ peptone, $1 \mathrm{~mL}$ of $1 \mathrm{mM}$ $\mathrm{FeSO}_{4}, 10 \mathrm{~mL}$ of $1.2 \% \mathrm{MgSO}_{4}, 1 \mathrm{~mL}$ of $0.01 \mathrm{M}$ $\mathrm{MnCl}_{2}, 1 \mathrm{~mL}$ of $1 \mathrm{M} \mathrm{Ca}\left(\mathrm{NO}_{3}\right)_{2}, 10 \mathrm{~mL}$ of $10 \% \mathrm{KCl}$ in $977 \mathrm{~mL}$ of ultrapure water) and incubated for 7 days at $37{ }^{\circ} \mathrm{C}$ with continuous agitation. Spores were collected by centrifugation at $10,000 \operatorname{RPM}(17,000 \mathrm{~g})$ for $30 \mathrm{~min}$ at $20{ }^{\circ} \mathrm{C}$. The spores were washed ten times in ultrapure water at $10,000 \mathrm{RPM}(17,000 \mathrm{~g})$ for $10 \mathrm{~min}$ to remove partially sporulated cells and vegetative bacteria. The state of sporulation was verified through phase contrast microscopy, and samples of prepared spores were considered to be clean and sporulated when at least $99 \%$ of spores examined under the microscope were phase bright. Spores were stored in water at $4{ }^{\circ} \mathrm{C}$.

\section{Polymer syntheses}

PEG-KBr 3 complex

PEG-400 and PEG-8000 specimens were complexed with $\mathrm{KBr}_{3}$ as described previously (Verma and Jain 2012; Verma et al. 2012). A solution of potassium tribromide was first obtained by adding $10 \mathrm{~g}$ of bromine to a chilled $35 \mathrm{wt} \%$ aqueous solution of $\mathrm{KBr}$ in water. Polymer ( $25 \mathrm{~g}$ for PEG- 400 and $75 \mathrm{~g}$ for PEG-8000) was added to the solution of potassium tribromide and stirred vigorously for $5 \mathrm{~h}$ at room temperature. The resulting solution was extracted twice with dichloromethane and the extracts dried over anhydrous sodium sulfate (Verma and Jain 2012). The dark orange red viscous liquid (PEG-400) or paste (PEG-8000) was obtained in 96-98\% yield. The loading of the $\mathrm{KBr}_{3}$ in the prepared PEG-400$\mathrm{KBr}_{3}$ and PEG-8000-KBr 3 complexes was found to be 1.4 and $2.1 \mathrm{mEq} / \mathrm{g}$ of polymer, respectively, using elemental analysis for bromine. The PEG- $\mathrm{KBr}_{3}$ materials were stored at $4{ }^{\circ} \mathrm{C}$ in the dark until use.

\section{Polyallylamine modified with 4-aminopyridine, hydrobromide salt}

1-(3-Amino-3-oxopropyl)-4-cyanopyridin-1-ium chloride (1) was first synthesized as described elsewhere (Curtis et al. 2000). For the polymer modification (Fig. 2), an aqueous solution containing $5.3 \mathrm{~g}(25 \mathrm{mmol})$ of (1) and $2.8 \mathrm{~g}$ polyallylamine $(50 \mathrm{mmol})(100 \mathrm{~mL}$ total $)$ was allowed to react under stirring at $40{ }^{\circ} \mathrm{C}$ for $4 \mathrm{~h}$. Then, $30 \mathrm{~mL}$ of $50 \%$ aqueous $\mathrm{NaOH}$ were added into the solution, which was stirred at $90^{\circ} \mathrm{C}$ for another $4 \mathrm{~h}$. The mixture was allowed to equilibrate at ambient temperature, the polymer was precipitated by acetone, redissolved in deionized water, and the solution was dialyzed against excess aqueous sodium methoxide $(\mathrm{pH} 8.5$, membrane MWCO, 12-14 kDa) and lyophilized. ${ }^{1} \mathrm{H}$ NMR (400 MHz, $\mathrm{D}_{2} \mathrm{O}$ ), $\delta$ (ppm): $1.1(\mathrm{~m}, \mathrm{CH}, \beta$ to $-\mathrm{N}), 2.61(\mathrm{~m}$, $\mathrm{CH}_{2} \alpha$ to $\left.-\mathrm{N}\right), 2.86,3.11\left(\mathrm{~m}, \mathrm{CH}_{2} \alpha\right.$ to $\left.-\mathrm{N}-\mathrm{CR}\right), 5.95,6.1$ (m, secondary $-\mathrm{NH}), 6.5$ ( $\mathrm{m}$, pyridine), 7.9, 8.5 ( $\mathrm{m}, 2 \mathrm{H}$ pyridine). Using integrations of signals at 2.61 (methylene of allylamine) to $8.5 \mathrm{ppm}$ (pyridine), it was estimated that the degree of polyallylamine modification was approximately $50 \mathrm{~mol} \%$. That is, $50 \%$ of the polymer $-\mathrm{NH}_{2}$ groups were substituted with 4-aminopyridine.

Bromination of polyallylamine modified with 4aminopyridine (PAAm-APy) was accomplished as follows (Bromberg et al. 2014). Dry polymer was suspended in a dark brown glass tube with chilled, freshly prepared $15 \mathrm{wt} \%$ bromine solution in carbon tetrachloride at $0{ }^{\circ} \mathrm{C}$ under constant stirring in the dark. The suspension was sealed and brought up to ambient temperature within $4 \mathrm{~h}$ under stirring, which continued for another $20 \mathrm{~h}$. The suspension was washed by $1 \mathrm{M}$ $\mathrm{NaOH}$, ethanol, and acetone, and the solids were separated by 
Fig. 2 Synthesis of polyallylamine modified by 4-aminopyridine (PAAm-APy) followed by de-quaternization

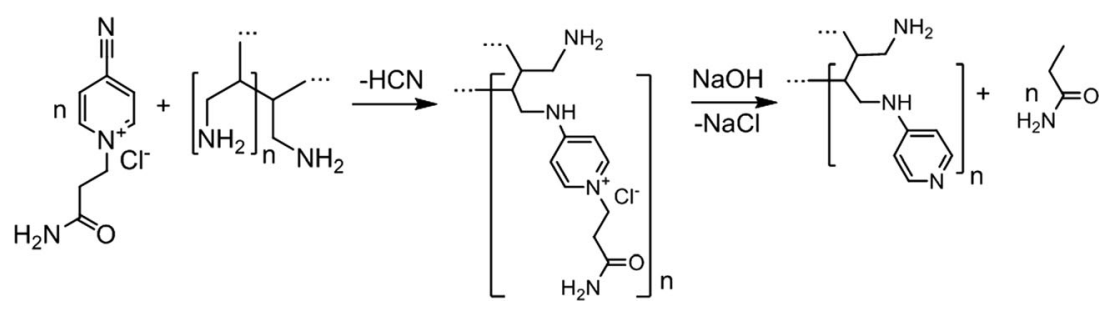

suction filtration using Gelman borosilicate glass membranes with effective pore size of $0.7 \mu \mathrm{m}$. The yellow solids were again washed by carbon tetrachloride and ethanol and dried over anhydrous sodium sulfate. The bromine content of this polymer was found to be $4.2 \mathrm{mEq} / \mathrm{g}$ polymer based on elemental analysis. The brominated polymer (PAAm-APy-HBr) was stored at $4{ }^{\circ} \mathrm{C}$ in the dark until use.

\section{Polyvinylpyrrolidone-hydrotribromide adduct}

Polyvinylpyrrolidone (PVP)-bromine complex was prepared by the bromination of commercially available linear PVP by a bromine solution in carbon tetrachloride (Bromberg et al. 2014). Dry PVP (1 g) was suspended in an amber glass test tube with a freshly prepared $15 \mathrm{wt} \%$ bromine solution (chilled) in carbon tetrachloride $(10 \mathrm{~mL})$. The solution was stirred in the dark at $0{ }^{\circ} \mathrm{C}$ overnight. The suspension was then sealed and brought up to ambient temperature within $4 \mathrm{~h}$ with continuous stirring, and stirring was continued for an additional $20 \mathrm{~h}$. The brominated suspension was washed with ethanol and acetone. The solids were separated by filtration using Gelman borosilicate glass membranes with a pore size of $0.7 \mu \mathrm{m}$ and washed by carbon tetrachloride followed by ethanol and deionized water. The solids were then dried over anhydrous sodium sulfate and kept at $4{ }^{\circ} \mathrm{C}$ in the dark until use. Bromine content in the resulting brominated PVP was measured by elemental analysis and was found to be $3.7 \mathrm{mEq} / \mathrm{g}$ of polymer. The analysis for bromine was conducted in a commercial laboratory using EPA Method 5050/9056, involving bomb combustion followed by ion chromatography.

\section{Inactivation of $B$. anthracis Sterne with brominated polymers}

To determine the effects of brominated polymers on $B$. anthracis Sterne inactivation, spores at a concentration of $10^{8}$ spores $/ \mathrm{mL}$ were exposed to various concentrations of brominated polymers dissolved in water, control polymers in water or just ultrapure water for $5 \mathrm{~min}$ at $25^{\circ} \mathrm{C}$. After treatment, the spores were washed three times in water by centrifugation at $5000 \mathrm{RPM}(8500 \mathrm{~g})$ for $10 \mathrm{~min}$ and serially diluted. To ensure that the brominated compound had been completely removed, we tested the amount of bromine left after washing the spore solution by centrifugation. Samples of the washed spore solution were analyzed by inductively coupled plasma atomic emission spectrometry (ICP-AES; ALS Environmental, Tucson, AZ). The detection limit for bromine for this particular method was $1 \mathrm{ppm}$ or $1 \mathrm{mg} / \mathrm{L}$ in the spore solution. Using ICP-AES, we determined that none of the samples contained any measurable amount of bromine suggesting that the inactivating agent had been completely removed during the washing and before plating. A $100 \mu \mathrm{L}$ of spore solution was inoculated onto tryptic soy agar plates and incubated overnight at $37^{\circ} \mathrm{C}$. The number of colony-forming units (CFU) on the agar plates was determined. Three independent experiments were done, and the data were analyzed using the Kruskal-Wallis one-way analysis of variance (ANOVA) on ranks for repeated measurements. Dunnett's test was used for comparisons between water-treated spores and those treated with polymers. A difference was significant if $P<0.05$.

\section{Monitoring the release of DPA from B. anthracis Sterne after exposure to brominated polymers}

The release of DPA from $B$. anthracis was monitored by timeresolved fluorescence intensity measurements. PVP-Br, PEG400-Br, PEG-8000-Br, and PAAm-APy-Br were suspended in water at a concentration of $32 \mathrm{mg} / \mathrm{mL}$, covered, and left shaking at room temperature in the dark for $60 \mathrm{~min}$. After incubation, the polymer solution was filtered through a $0.2-\mu \mathrm{m}$ syringe filter, and $75 \mu \mathrm{L}$ of the filtered solution was placed inside the wells of a black 96-well plate. The polymer solution was combined with a freshly made solution of $4 \mathrm{mM}$ terbium chloride $\left(\mathrm{TbCl}_{3}\right)$. $\mathrm{TbCl}_{3}$ reacts with DPA released from spores during germination and forms the chelate terbium dipicolinate $\left(\mathrm{Tb}(\mathrm{DPA})_{3}\right)^{3-}$, which luminesces with UV excitation (Rosen 2006). After addition of $\mathrm{TbCl}_{3}$ to the plate, B. anthracis Sterne at various concentrations of $10^{6}, 10^{5}$, and $10^{4}$ spores $/ \mathrm{mL}$ in water were immediately added to each well. Final number of spores in each well was $2 \times 10^{5}, 2.5 \times 10^{4}$, and $2.5 \times 10^{3}$. Final concentration of the polymer in each well was $12 \mathrm{mg} / \mathrm{mL}$. The plate was set to shake for $5 \mathrm{~s}$, and the solution was excited at $270 \mathrm{~nm}$. Emission was collected at $546 \mathrm{~nm}$ every $5 \mathrm{~min}$ for up to $1 \mathrm{~h}$ using a Gemini XPS microplate spectrofluorometer (Molecular Devices, Toronto, Canada). The experiment was done in triplicate, and the average percent release DPA was reported.

Percent of DPA released was calculated by monitoring the release of DPA from $B$. anthracis Sterne after exposure to 
$2 \mathrm{mM}$ dodecylamine for $5 \mathrm{~h}$. The fluorescence signal obtained after $5 \mathrm{~h}$ of exposure was assumed to correspond to the total amount of DPA released from the spores since this signal did not change in the course of an hour following exposure.

\section{Atomic force microscopy and electron scanning microscopy}

AFM and SEM were used to evaluate the changes in morphology of B. anthracis before and after exposure to PVP-Br and control PVP. The polymers were dissolved in water for $60 \mathrm{~min}$ with continuous shaking and passed through a $0.2-\mu \mathrm{m}$ filter. The filtered solution was mixed with $B$. anthracis Sterne spores at a concentration of $10^{6}$ spores $/ \mathrm{mL}$ for $5 \mathrm{~min}$ at room temperature. This is the condition where all spore inactivation was done, and this corresponds to looking at inactivated spores by AFM and SEM. After exposure to the polymer, the spore-polymer solution was centrifuged and washed with water, and spores were resuspended in ultrapure water. A $5-\mu \mathrm{L}$ solution of polymer-treated $B$. anthracis Sterne was placed on a silicon wafer and left to air-dry for $48 \mathrm{~h}$ before imaging.

Images were collected using AFM (Dimension Icon, Bruker Corp., Santa Barbara, CA) that was operated in ScanAsyst mode. Triangular cantilevers with silicon nitride tips having a spring constant of $0.4 \mathrm{~N} / \mathrm{m}$ and a resonant frequency of $70 \mathrm{kHz}$ were used (ScanAsyst-Air, Bruker Corp.). Images were captured with scan areas of $5 \mu \mathrm{m}^{2}$. All images were captured at a scan rate of $1 \mathrm{~Hz}$ and with a resolution of $512 \times 512$ points.

For imaging with SEM, the silicon chip with spores was coated with a $\sim 20$-nm coating of gold-palladium for $180 \mathrm{~s}$ before imaging. SEM micrographs were taken with a Zeiss EVO60 at a 10KX magnification at $30 \mathrm{kV}$ and a working distance of $6 \mathrm{~mm}$.

\section{Results}

Brominated polymers tested for their interaction with $B$. anthracis Sterne spores are depicted in Fig. 3. The content of bromine loaded into the polymeric species decreased in the sequence PAAm-APy-Br $>$ PVP-Br $>$ PEG-8000-Br $>>$ PEG-400-Br with PAAm-APy-Br having the highest bromine content of $4.2 \mathrm{mEq} / \mathrm{g}$ of polymer and PEG-400-Br having the lowest content of $1.6 \mathrm{mEq} / \mathrm{g}$ of polymer (Table 1 ). This means that the content of bromine in our polymers ranges from $\sim 13 \%$ in PEG-400 to $\sim 34 \%$ in PAAm-APy, and the remainder corresponds to the organic polymer. The bromine content in our polymers varied due to the different bromine concentrations used during the complex synthesis procedures as well as the varying nature of the polymers (polycationic PAAm-APy versus neutral PEG and PVP).

\section{Inactivation of $B$. anthracis spores after exposure to brominated polymer networks}

We characterized the inactivation of $B$. anthracis Sterne spores exposed to PVP, PAAm, PEG-400, PEG-8000, and their brominated counterparts to evaluate their activity against spores. For this study, inactivation was defined as the process that results in spores being unable to grow in regular media, such as tryptic soy broth, after exposure to the polymers. Control polymers (those not brominated) did not cause any inactivation of $B$. anthracis spores even after prolonged exposure to the polymers (Fig. 4). However, treatment of B. anthracis Sterne spores with brominated polymers caused significant inactivation of spores (Fig. 4).

A concentration of brominated polymers of $4 \mathrm{mg} / \mathrm{mL}$ (effective bromine concentration: $512-1342 \mathrm{ppm}$ ) caused between 1.8 and $2.8 \log$-kills in $5 \mathrm{~min}$ of exposure to the brominated polymers. However, significantly higher inactivation of spores was achieved with brominated polymers at a concentration of $>12 \mathrm{mg} / \mathrm{mL}$ where log-kills of 8 were observed for all polymers. No statistical difference was found between the number of surviving spores after exposure to 12,24 , or $50 \mathrm{mg} /$ $\mathrm{mL}$ for polymers PAAm-Br, PEG-400-Br, and PEG-8000-Br, making $12 \mathrm{mg} / \mathrm{mL}$ of brominated polymers the minimum concentrations needed to cause log-kills of 8 . A statistical difference was observed between spores exposed to $12 \mathrm{mg} / \mathrm{mL}$ of brominated PVP and spores exposed to 24 and $50 \mathrm{mg} / \mathrm{mL}$ brominated PVP. Since a concentration of $12 \mathrm{mg} / \mathrm{mL}$ of brominated polymers caused significant inactivation of B. anthracis Sterne in $5 \mathrm{~min}$, this concentration of brominated

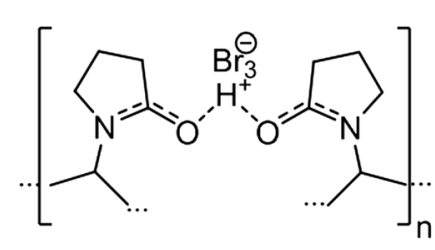

a

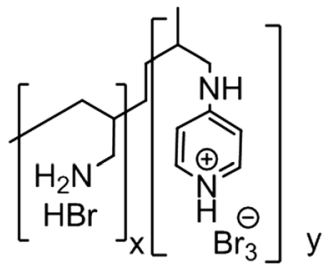

b

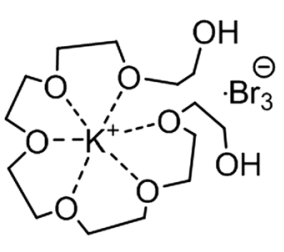

C

Fig. 3 Chemical structures of brominated polymer adducts synthesized for sensing and deactivation of B. anthracis Sterne. a PVP-hydrobromic acid adducts. b Brominated PAAm modified by 4-aminopyridine. $\mathbf{c}$ PEG complexed with $\mathrm{KBr}_{3}$ 
Table 1 Bromine content within brominated polymers

\begin{tabular}{llll}
\hline $\begin{array}{l}\text { Brominated } \\
\text { polymer }\end{array}$ & $\begin{array}{l}\mathrm{mEq} \mathrm{Br} / \mathrm{g} \\
\text { of polymer }^{\mathrm{a}}\end{array}$ & $\begin{array}{l}\text { wt\% Br in } \\
\text { polymer }\end{array}$ & $\begin{array}{l}\mathrm{ppm} \text { of } \mathrm{Br} \text { in } \\
12 \mathrm{mg} / \mathrm{mL} \text { polymer }\end{array}$ \\
\hline PVP-Br & 3.7 & 29.5 & 3540 \\
PEG-400-Br & 1.6 & 12.8 & 1536 \\
PAAm-APy-Br & 4.2 & 33.9 & 4026 \\
PEG-8000-Br & 3.0 & 23.9 & 2868 \\
\hline
\end{tabular}

${ }^{\mathrm{a}}$ Milliequivalents (or mmol) of bromine per gram of polymer

and unbrominated polymers was chosen for the rest of our experiments.

\section{Morphology changes of $B$. anthracis Sterne after exposure to PVP-Br}

The rapid and effective inactivation of $B$. anthracis Sterne observed in our study prompted an investigation of the morphology of spores after exposure to brominated polymers. Untreated B. anthracis Sterne spores were generally ellipsoidal in shape measuring $\sim 1.5-2 \mu \mathrm{m}$ long and $0.75-1 \mu \mathrm{m}$ wide (Fig. 5a, d). During AFM and SEM experiments, untreated spores were found in small aggregates that probably formed as the sample was air-dried on the silicon wafer (Fig. 5a). Rodlet structures were observed on the surface of untreated B. anthracis Sterne spores (Fig. 5d). These structures are typical of these spores and are thought to form during sporulation (Plomp et al. 2005a, b). All untreated spores appeared intact with no visible pores, holes, grooves, or breakages on the spore surface.

Treatment of $B$. anthracis Sterne with brominated polymer (Fig. 5b, e) or with the control polymer (Fig. 5c, f) for $5 \mathrm{~min}$ resulted in a thick coating surrounding the spores. This thick

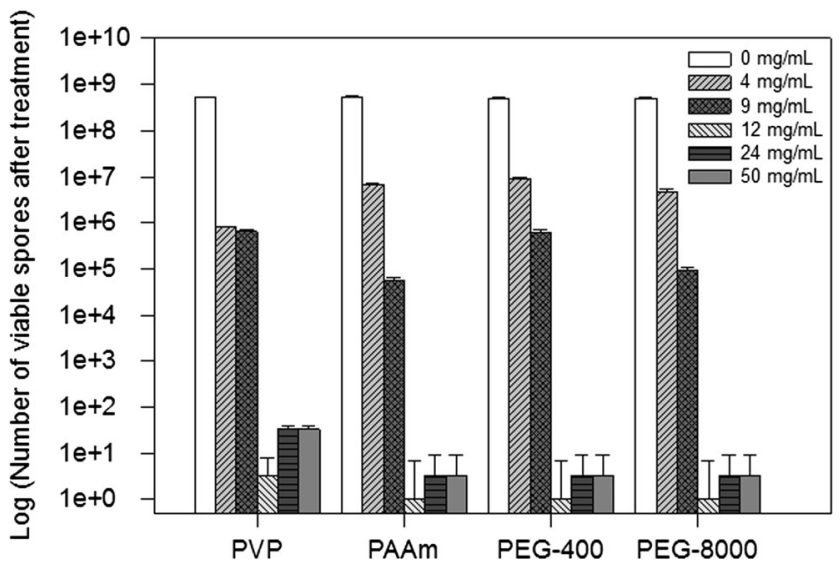

Fig. 4 Average number of surviving $B$. anthracis Sterne spores after exposure to brominated polymers for $5 \mathrm{~min}$. Spores at a concentration of $10^{9}$ spores $/ \mathrm{mL}$ were exposed to increasing concentrations of brominated polymers for $5 \mathrm{~min}$ at $23{ }^{\circ} \mathrm{C}$ coating could not get removed with washing by centrifugation, or resuspension and mixing in ultrapure water. In addition, inductively coupled plasma atomic emission spectrometry (ICP-AES) was done to analyze the spore solution after washing had taken place (ALS Environmental, Tucson, AZ). Through ICP-AES, we were able to determine that the sample of spores treated with the brominated compound had no bromine present after washing and preparation of the spores for AFM or SEM imaging. This suggests that only polymer remains in the solution and it strongly attaches to the cells. This thick coating prevented us from observing characteristic properties of the spore surface as it completely surrounded all spores. No ridges or rodlets could be clearly identified on the surface of the spore. However, through both AFM and SEM, the coating and the spore underneath the coating were observed. Section analysis of height AFM images revealed that this coating was 145 to $311 \mathrm{~nm}$ thick, which explained why characteristic features of the spore surface, such as rodlets, could not be clearly observed. Further drying of the sample did not remove or break this coat. The sample was left drying for up to 2 weeks, and similar morphologies were observed.

\section{Release of DPA from $B$. anthracis spores after treatment with brominated polymers}

A study was carried out to assess whether B. anthracis Sterne spores could be detected in the presence of brominated polymers by sensing the release of DPA from the spore core. Timeresolved fluorescence was used to follow DPA release from spores after exposure to brominated polymers. Exposure of B. anthracis Sterne to control polymers (not brominated) did not result in the release of DPA from spores, and the fluorescence signal remained constant for the duration of the experiment (Fig. 6). Furthermore, the fluorescence intensity of the spores exposed to the control polymers was very similar to the intensity obtained for spores not treated with polymers. The lack of change in fluorescence signal indicates that there was no DPA release from spores and that $B$. anthracis remained dormant and viable.

Changes in fluorescence intensity and an increase in DPA release were observed after exposure of $B$. anthracis Sterne spores to all brominated polymers. The fluorescence signal increased over time indicating the progressive release of DPA from spores (Fig. 6). Spores exposed to brominated PVP and brominated PEG-8000 caused a $64 \%$ and a $60 \%$ release of DPA from the spore in $1 \mathrm{~h}$, respectively. Exposure of spores to brominated PAAm and brominated PEG-400 resulted in the release of $\sim 10$ and $\sim 18 \%$ of DPA after $60 \mathrm{~min}$, respectively (Fig. 6). While the release of DPA from spores was significant after 60 min of exposure for some of our polymers, it was possible to start noticing this release only after 10 min of contact with the brominated polymer. This sensing 
Fig. 5 Representative AFM and SEM images of $B$. anthracis Sterne before $(\mathbf{a}, \mathbf{d})$ and after exposure to $12 \mathrm{mg} / \mathrm{mL}$ of filtered brominated PVP $(\mathbf{b}, \mathbf{e})$ and unbrominated PVP $(\mathbf{c}, \mathbf{f})$ for $5 \mathrm{~min}$ at $23{ }^{\circ} \mathrm{C}$. Peak force error AFM images $(\mathbf{a}, \mathbf{b}, \mathbf{c})$ were obtained in ScanAsyst mode in air at room temperature with a scan size of $5 \mu \mathrm{m} \times 5 \mu \mathrm{m}$. SEM micrographs (d, e, f) were obtained at $30 \mathrm{kV}$ and a working distance of $6 \mathrm{~mm}$. Polymer can be seen encasing the spores (white arrows)
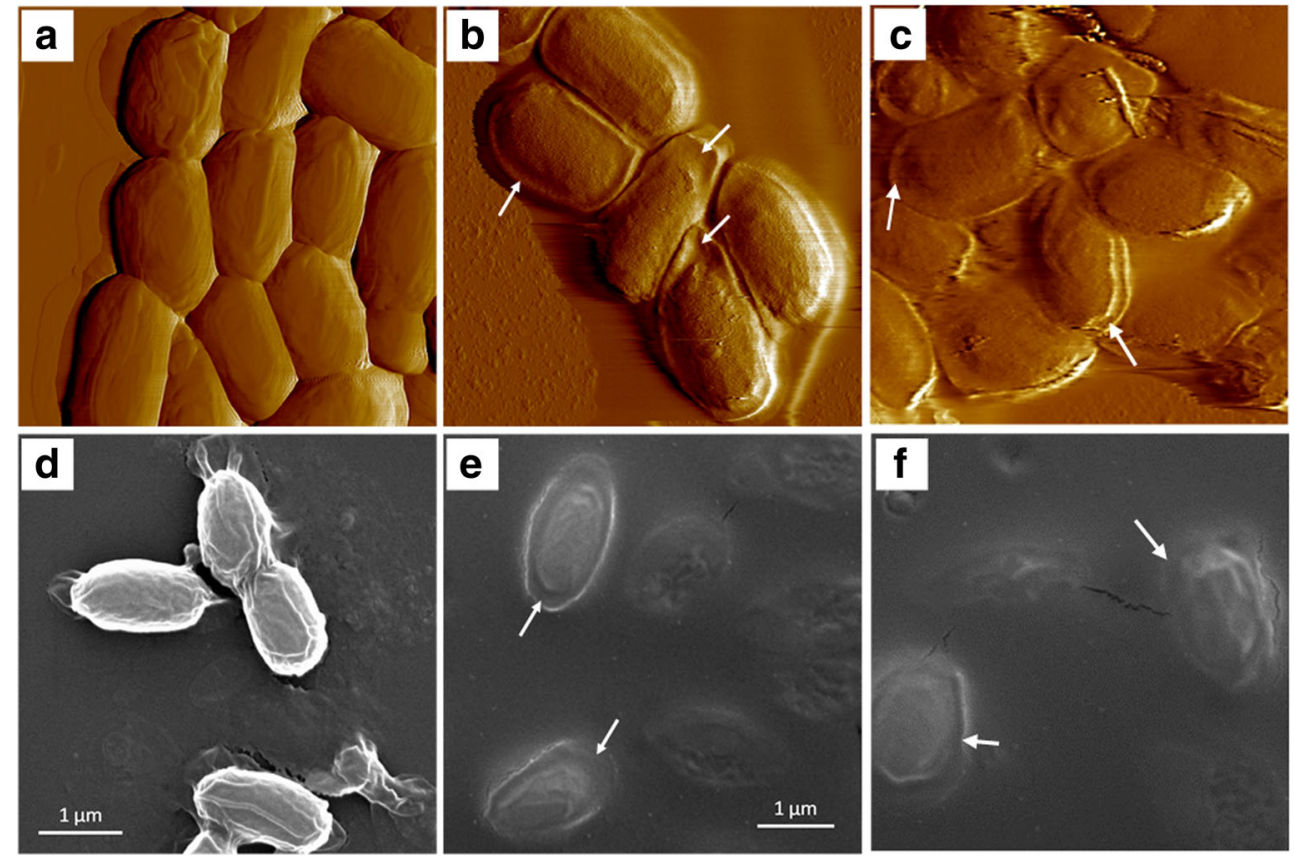

a

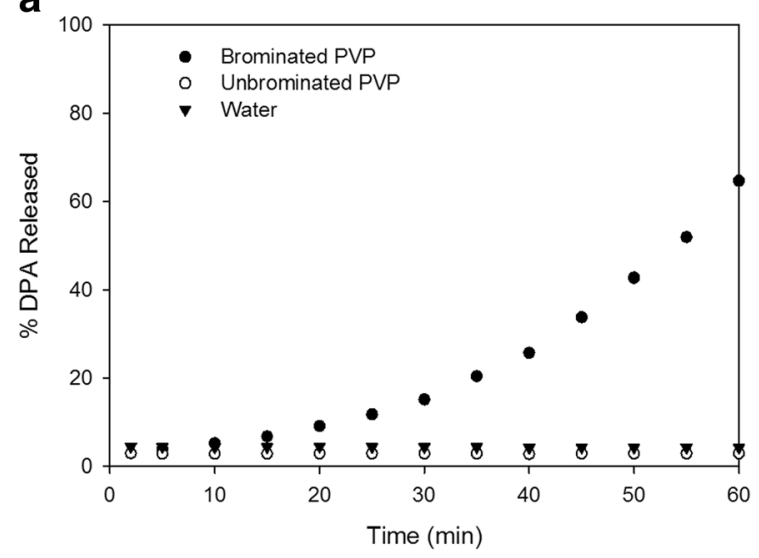

C

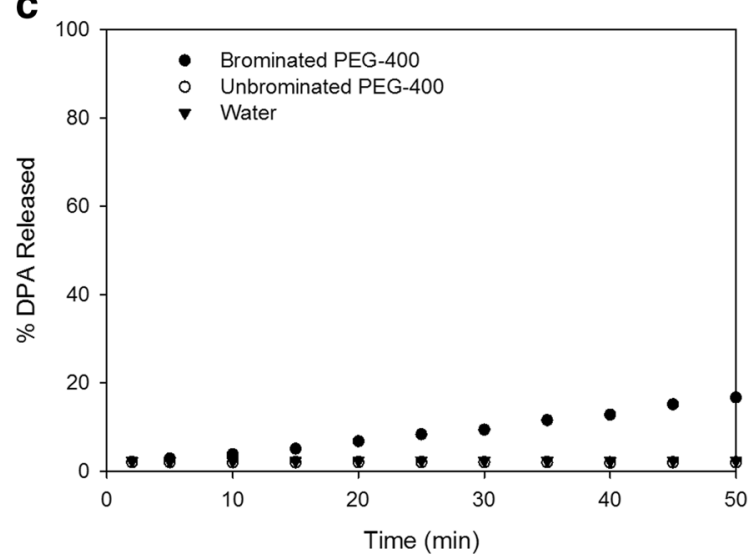

Fig. 6 Average percent DPA release from 200,000 B. anthracis Sterne spores exposed to $12 \mathrm{mg} / \mathrm{mL}$ of brominated polymer, $12 \mathrm{mg} / \mathrm{mL}$ of unbrominated polymer, and control (spores incubated without polymers) for a PVP, b PAAm, c PEG-400, and d PEG-8000. Time- b

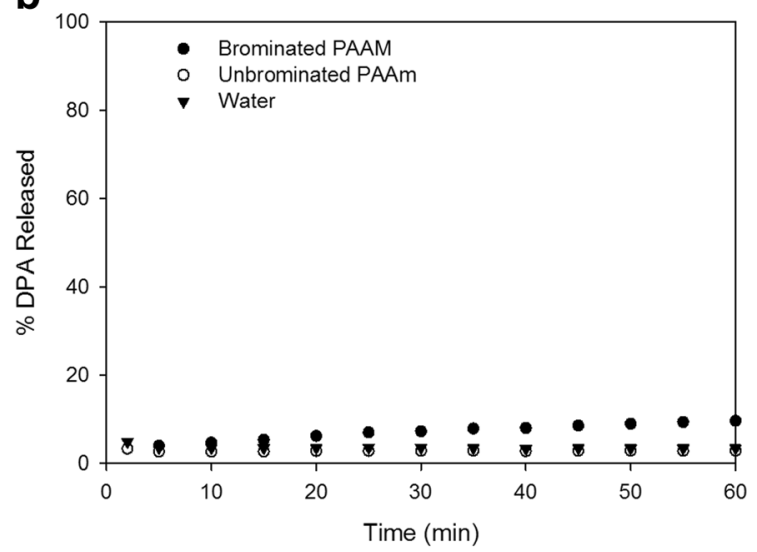

d

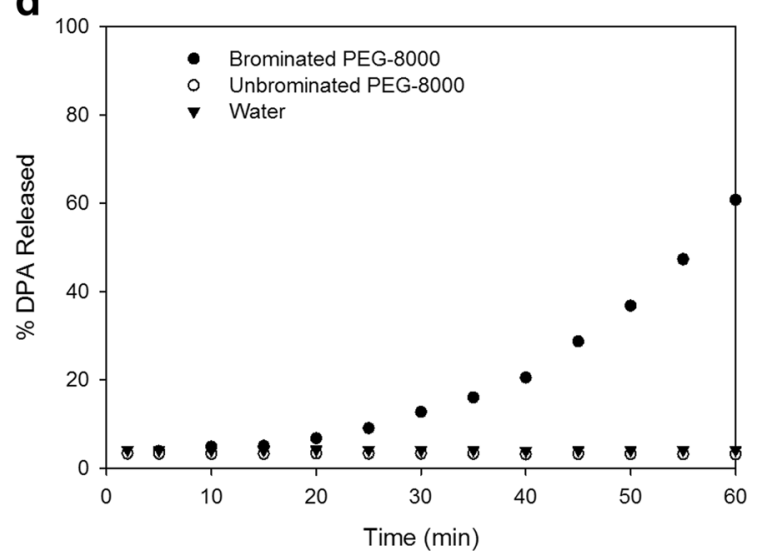

resolved fluorescence readings were taken every $5 \mathrm{~min}$ for up to $1 \mathrm{~h}$ at $23{ }^{\circ} \mathrm{C}$. Spectrofluorometer was set at 270 -nm excitation wavelength, and emission was collected at $546 \mathrm{~nm}$. Experiments were done in triplicate 
method confirms that an action, such as inactivation of spores, has already occurred. Inactivation of spores, which took place in under $5 \mathrm{~min}$, takes place first before detectable levels of DPA start getting released from the spore.

We also examined how the number of spores present in the solution with brominated polymers relates to amounts of DPA released from the spore (Fig. 7). Our results showed that the amount of DPA being released from B. anthracis Sterne increased with decreasing number of spores (Fig. 7). For instance, exposure of 2500 spores to brominated PEG- 8000 resulted in up to $87 \%$ DPA release after an hour of treatment. On the contrary, only up to $65 \%$ of DPA was released after exposure of 200,000 B. anthracis Sterne spores to the same concentration of the brominated polymer.

The limits of detection of our system allowed us to see changes in the fluorescence intensity in samples that contained more than 2500 spores. It was possible to clearly detect DPA release from 2500 spores after exposure to PAAm-APy-Br and PEG-8000-Br; however, these low concentrations were more difficult to detect after exposure to PVP-Br and PEG$400-\mathrm{Br}$. Nevertheless, detection of DPA release from spores was possible for all polymer systems.
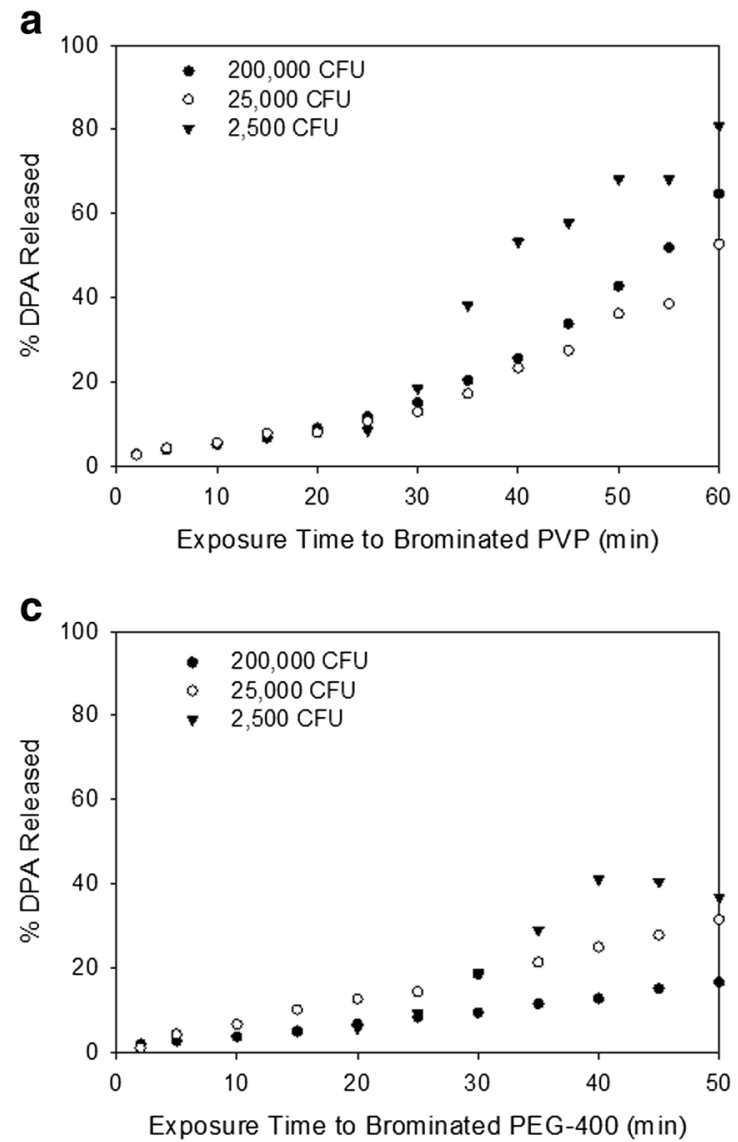

Fig. 7 Average percent DPA release from $B$. anthracis Sterne spores as a function of spore concentrations after exposure to $12 \mathrm{mg} / \mathrm{mL}$ of brominated polymer for a PVP, b PAAm, c PEG-400, and d PEG-8000. Time-resolved fluorescence readings were taken every $5 \mathrm{~min}$ for up to $1 \mathrm{~h}$

\section{Discussion}

The PVP-based complexes with halogens are well-known adducts (Schenck et al. 1979), which are the products of a direct addition of the halogen to PVP chains. The PEG-, PVP-, and polymer-supported vinylpyridine-hydrotribromide (pyridinium hydrobromide perbromide) complexes are widely utilized bromination and oxidation agents that have been applied in a plethora of industrially important reactions (Verma and Jain 2012; Verma et al. 2012; Awang and Wolfe 1969; Jain and Sain 2010). Polymeric hydrotribromide complexes can be considered to be a "solid bromine" and possess the ability to release bromine in a controlled manner. The brominated compound forms hypobromous acid $(\mathrm{HOBr})$ in water and organic solvents (Fig. 8). Hypobromous acid is highly unstable and is an active oxidizer used as a bleach, a deodorant, and a disinfectant capable of killing many pathogens (Gottardi et al. 2014; Heeb et al. 2014).

We tested the ability of four brominated polymer complexes to inactivate $B$. anthracis Sterne. We found that a concentration of $12 \mathrm{mg} / \mathrm{mL}$ of brominated complexes caused logkills of 8 in under $5 \mathrm{~min}$ of contact (Fig. 4). While $12 \mathrm{mg} / \mathrm{mL}$

b

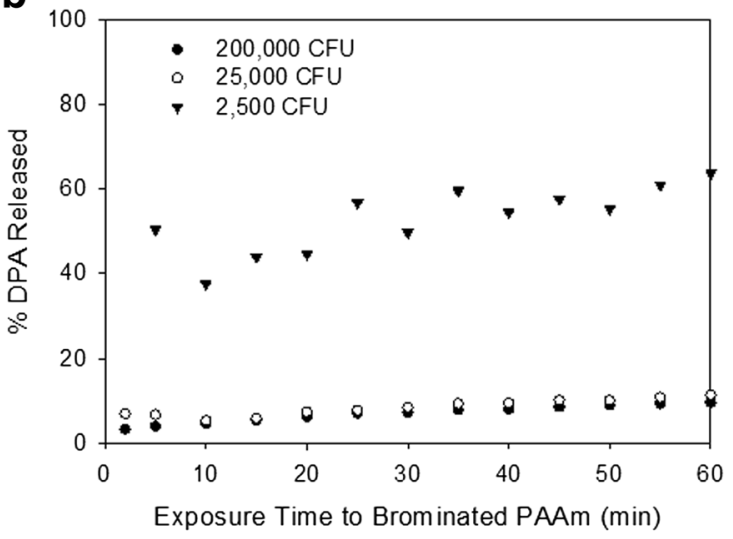

d

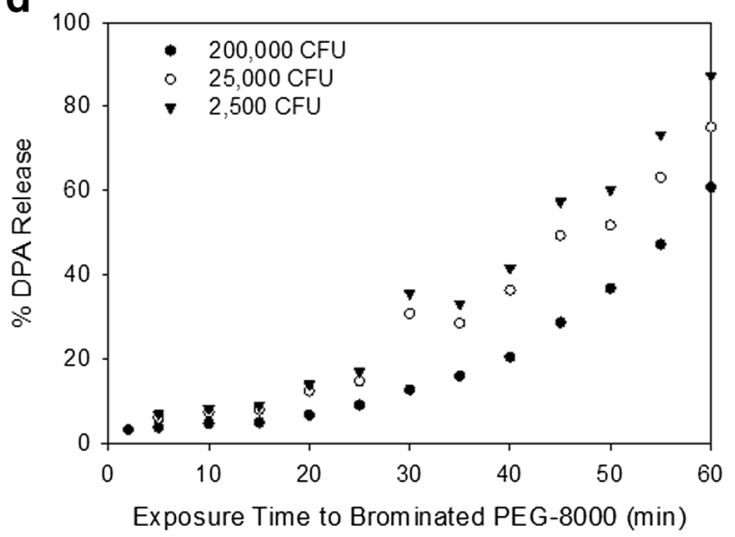

at $23{ }^{\circ} \mathrm{C}$. Spectrofluorometer was set at $270-\mathrm{nm}$ excitation wavelength, and emission was collected at $546 \mathrm{~nm}$. Experiments were done in triplicate 


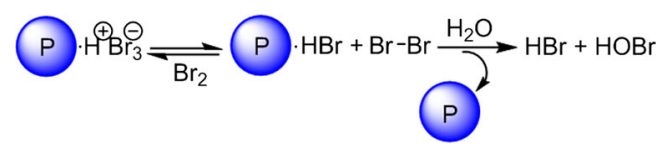

Fig. 8 Formation of hypobromous acid as a result of bromine release from a polymer (P)-hydrotribromide complex

of brominated polymers (effective bromine concentration, 1536-4026 ppm) may seem high for a common disinfectant, U.S. government agencies recommend the use of halogenated compounds, such as sodium hypochlorite, at concentrations greater than $5260 \mathrm{ppm}$ and contact time of $60 \mathrm{~min}$ at $20^{\circ} \mathrm{C}$ for the deactivation of Bacillus species (Young and Setlow 2003). For our study, only $1180 \mathrm{ppm}$ of available bromine $(4 \mathrm{mg} / \mathrm{mL}$ of PVP-Br) was needed to achieve a $2.5-\log$ reduction in $B$. anthracis Sterne in under $5 \mathrm{~min}$, and $\log$ reductions greater than 8 were observed with only $3540 \mathrm{ppm}$ of available bromine $(12 \mathrm{mg} / \mathrm{mL}$ of PVP-Br). Our results suggest that our brominated polymers are more effective than compounds such as sodium hypochlorite and also that less contact time between the active agent and spores is required to achieve high spore inactivation. It must be noted that the effective bromine concentration (i.e., the bromine introduced into the solution as a complex with a polymer) is not necessarily the bromine available for the spore inactivation in solution, as the bromine release and subsequent conversion into hypobromous acid that causes the sporicidal action are controlled both kinetically and by the polymer-tribromine dissociation constants. To our knowledge, this is the first time that brominated polymeric compounds have shown high spore inactivation activity against $B$. anthracis Sterne in a matter of minutes. Sporicidal properties of halogens have been known for years (Cousins and Allan 1967; Williams and Russell 1991; Stoimenov et al. 2003). While the mechanism of action of halogens against spores is not well understood, researchers have suggested that halogens may produce coat and cortex degradation in spores, which would allow halogens to enter the spore and oxidize proteins located on the inner membrane of the spore (Cousins and Allan 1967). In a previous study, the damage of the spore inner membrane by oxidative species was reported (Cortezzo et al. 2004). Spores exposed to non-lethal concentrations of chlorine dioxide and sodium hypochlorite, among others, were more susceptible to heat killing, and membrane permeability had been compromised (Cortezzo et al. 2004). Perhaps a similar mechanism occurs with our system, and the spore surface and spore integrity have been compromised by our brominated polymers, allowing hypobromous acid to act against the spore.

Time of killing of Bacillus spores with halogenated compounds has also been investigated (Williams and Russell 1991; Cousins and Allan 1967; Stoimenov et al. 2002). Sodium hypochlorite $(\mathrm{NaOCl})$ and sodium dichloroisocyanurate $(\mathrm{NaDCC})$ both at a concentration of
100 ppm were shown to kill $B$. subtilis spores with $\mathrm{NaDCC}$ causing a 4 log-kill in $\sim 30+$ min and $\mathrm{NaOCl}$ causing a 3 logkill in $\sim 5$ min (Williams and Russell 1991; Majcher et al. 2008). In another study, the iodophor Iosan $D$ at a concentration of $50 \mathrm{ppm}$ caused $99 \%$ of killing of Bacillus cereus after 20 min of exposure at $21{ }^{\circ} \mathrm{C}$ (Cousins and Allan 1967). Halogen-doped magnesium oxide nanoparticles loaded with $20 \mathrm{wt} \%$ halogen completely killed Bacillus megaterium bacteria in $20 \mathrm{~min}$ (Stoimenov et al. 2002). However, B. subtilis in their sporulated form were less susceptible to the particles, and after $20 \mathrm{~min}$ of exposure, only $61 \%$ of the spores had been killed (Stoimenov et al. 2002). While some of these studies show excellent killing capabilities against spores, the time required to obtain high log-kills is significant. In this study, our brominated polymers inactivated practically all B. anthracis Sterne in their sporulated state in less than $5 \mathrm{~min}$ (Fig. 4). These inactivation properties make the active bromine-containing polymers potential candidates for selfdetoxifying compounds to eradicate spores on contact.

Exposure of $B$. anthracis Sterne spores to brominated polymers also resulted in a thick coating of polymer surrounding the spores that could not get removed during washing of spores as it was observed by both SEM and AFM (Fig. 5). Since analytical testing showed that no bromine was present after washing of the spores, this suggests that only polymer remains in the solution and it strongly attaches to the spores. The complete coating of spores by polymer suggests that $B$. anthracis spores could be trapped within the polymer network, making it an ideal candidate for the sequestration of B. anthracis on a polymeric surface. Our ability to cross-link the polymer with other species to make the polymers insoluble in water broadens the application of these brominated polymers so they can be used not only in solution but possibly as coatings or thin films incorporated in fabrics (Bromberg et al. 2014).

While the thickness of the polymer coat was significant, it is interesting to find that the coat did not play a role in protecting the spore against the bromine compound since all the spores treated with the bromine polymer were completely inactivated and could not be grown in regular media. It is possible that the polymer coating had ample spacing for hypobromous acid to pass through the polymer coat and act against the spore or that hypobromous acid acted against the spore before the polymer coated the cells. However, whatever the case may be, no morphological differences were observed between the spores exposed to brominated or control polymers.

In addition to investigating the sporicidal activity of brominated polymers against spores, a study was carried out to assess whether spores can be detected in the presence of brominated polymers. DPA is a unique compound found in spores that aids the organism in maintaining its dormant state when nutrients are not available (Setlow 2003). Because of 
this uniqueness, DPA can be used as a way to detect the presence of Bacillus spores in a solution of bacteria. During our experiments, it was observed that there was a release of DPA from spores after exposure to brominated polymer (Fig. 6). However, detectable levels of DPA were only observed after the spores had already been inactivated and continued for a prolonged period of time after inactivation of $B$. anthracis Sterne. While DPA release is usually associated with germination of spores, DPA release after inactivation of spores is not an unusual event, and it has been observed by others (Coleman et al. 2007; Pinzón-Arango et al. 2013; PinzónArango et al. 2009). DPA release was shown to take place more slowly than killing of $B$. cereus, B. subtilis, and $B$. megaterium after treatment with moist heat (Coleman et al. 2007). In Bacillus atrophaeus, the majority of DPA release took place after more than $99 \%$ of spores had been killed with dodecylamine (Pinzón-Arango et al. 2009). While it is not fully understood why DPA release takes place long after inactivation with brominated polymers, some studies have suggested that release of DPA after killing may be due to damage of important proteins in the inner membrane that results in the release of DPA (Coleman et al. 2007). However, in previous studies, this loss of DPA was rapid and an all-or-nothing event. In our study, not all of the DPA gets released under an hour, and in the presence of some of the polymers, such as brominated PEG-400 and brominated PAAm, very little DPA gets released. As it has been suggested by other studies (Coleman et al. 2007), different membrane proteins may be deactivated at different rates. It is possible that the slow and incomplete release of DPA in our study may be due to some of the membrane proteins being affected by the brominated polymer, but not others. The dissociation of bromine from the polymer may be different for all the polymers in our study, and it could be dependent on molecular weight of the polymer resulting in some polymer releasing bromine into the spore solution faster than others and, therefore, acting at different rates with the spores. The different kinetics of DPA release observed in our study need to be further investigated in future studies. However, our study shows that DPA release after exposure to brominated polymers can be used as a method of detection for $B$. anthracis Sterne spores even after spores had been inactivated.

During our study, we also examined if the percent of DPA release was related to the number of spores being present in the solution (Fig. 7). Interestingly, our results showed that the percent of DPA released from spores increased with decreasing number of $B$. anthracis spores. The large range of percent DPA released from low spores numbers may be due to the different amounts of bromine loaded into each polymer, different bromine release rates from the polymer, and the molecular weight of the bare polymer. Indeed, brominated PEG-400 had the lowest amount of bromine present and the lowest molecular weight of polymer, and it resulted in the lowest percentage of DPA being released from the 2500 spores at $\sim 36 \%$. Also, a solution with a low number of spores will have more bromine available to affect each spore compared to solutions of spores that contain a high number of bacteria. More bromine being available in the solutions with 2500 spores may result in more damage to the membrane of the spores, resulting in more DPA being released.

In summary, we have designed, synthesized, and characterized a set of polymeric compounds that have the capability of killing $B$. anthracis Sterne spores on contact. This is the first study, to our knowledge, to demonstrate that brominated polymers can kill B. anthracis Sterne in its sporulated state without the need to germinate spores first.

We obtained an $8 \log$-kill of $B$. anthracis Sterne in 5 min of exposure to the brominated polymers. This level of inactivation of B. anthracis has not been observed before. Furthermore, we showed that strong attractive interactions occur between spores and brominated polymers. Once the polymer has attached to the spores, bromine dissociates from the polymer complex in water, generating hypobromous acid. The released bromine species may cause partial damage to the spore coat, causing the inactivation of $B$. anthracis. Furthermore, we demonstrated the ability of brominated polymers to cause the release of DPA from the spores. This DPA release can be monitored through time-resolved fluorescence and can be used as a sensing system for the detection of $B$. anthracis spores. In addition, we observed the prolonged DPA released from spores even after inactivation, suggesting that spores may be detected for long periods of time following inactivation. The materials described in this paper may be an alternative compound for the design of detection and inactivation methods against $B$. anthracis spores.

Acknowledgments We are grateful to Drs. Peter Setlow, Ericka NJ Ford, and Ramanathan Nagarajan for the helpful discussions regarding this project.

Compliance with ethical standards This work was financially supported by the Defense Threat Reduction Agency (DTRA).

Conflict of interest The authors declare that they have no competing interests.

Ethical approval This article does not contain any studies with human participants of animals performed by any of the authors.

\section{References}

Amitai G, Murata H, Andersen JD, Koepsel RR, Russell AJ (2010) Decontamination of chemical and biological warfare agents with a single multi-functional material. Biomaterials 31:4417-4425

Awang DVC, Wolfe S (1969) Pyrrolidone hydrotribromide: a brominating agent with selectivity for ketones. Can J Chem 47:706-709 
Bromberg L, Pomerantz N, Schreuder-Gibson H, Hatton TA (2014) Degradation of chemical threats by brominated polymer networks. Ind Eng Chem Res 53:18761-18774

Cheung HY, Cui JX, Sun SQ (1999) Real-time monitoring of Bacillus subtilis endospore components by attenuated total reflection Fourier-transform infrared spectroscopy during germination. Microbiology 145:1043-1048

Coleman WH, Chen D, Li YQ, Cowan AE, Setlow P (2007) How moist heat kills spores of Bacillus subtilis. J Bacteriol 189:8458-8466

Cortezzo DE, Koziol-Dube K, Setlow B, Setlow P (2004) Treatment with oxidizing agents damages the inner membrane of spores of Bacillus subtilis and sensitizes spores to subsequent stress. J Appl Microbiol 97:838-852

Coulliette AD, Peterson LA, Mosberg JA, Rose JB (2010) Evaluation of a new disinfection approach: efficacy of chlorine and bromine halogenated contact disinfection for reduction of viruses and microcystin toxin. AmJTrop Med Hyg 82:279-288

Cousins CM, Allan CD (1967) Sporicidal properties of some halogens. J Appl Bacteriol 30:168-174

Curtis J, Hopper C, Murugan R, Huckstep L, Scriven E (2000) Supernucleophilic 4-Substituted-Pyridine catalysts, and processes useful for preparing same. U.S. Patent 6,046,336, 4 April 2000

Driks A (1999) Bacillus subtilis spore Coat. Microbiol Mol Biol Rev 63: $1-20$

Foster SJ, Johnstone K (1990) Pulling the trigger: the mechanism of bacterial spore germination. Mol Microbiol 4:137-141

Gottardi W, Klotz S, Nagl M (2014) Superior bactericidal activity of Nbromine compounds compared to their $\mathrm{N}$-chlorine analogues can be reversed under protein load. J Appl Microbiol 116:1427-1437

Heeb MB, Criquet J, Zimmermann-Steffens SG, Von Gunten U (2014) Oxidative treatment of bromide-containing waters: formation of bromine and its reactions with inorganic and organic compounds-a critical review. Water Res 48:15-42

Henriques AO, Moran CP Jr (2000) Structure and assembly of the bacterial endospore coat. Methods 20:95-110

Hilgren J, Swanson KM, Diez-Gonzalez F, Cords B (2007) Inactivation of Bacillus anthracis spores by liquid biocides in the presence of food residue. Appl Environ Microbiol 73:6370-6377

Jain SL, Sain B (2010) Application of N-methylpyrrolidin-2-one hydrotribromide in organic synthesis. Russ Chem Rev 79:683-692

Lenoir S, Pagnoulle C, Detrembleur C, Galleni M, Jerome R (2006) New antibacterial cationic surfactants prepared by atom transfer radical polymerization. J Polym Sci, Part A: Polym Chem 44:1214-1224

Leuschner RGK, Ferdinando DP, Lillford PJ (2000) Structural analysis of spores of Bacillus subtilis during germination and outgrowth. Colloids Surf, B 19:31-41

Lin J, Tiller JC, Lee SB, Lewis K, Klibanov AM (2002) Insights into bactericidal action of surface-attached poly(vinyl-Nhexylpyridinium) chains. Biotechnol Lett 24:801-805

$\mathrm{Lu}$ L, Rininsland FH, Wittenburg SK, Achyuthan KE, Mcbranch DW, Whitten DG (2005) Biocidal activity of a light-absorbing fluorescent conjugated polyelectrolyte. Langmuir 21:10154-10159

Majcher MR, Bernard KA, Sattar SA (2008) Identification by quantitative carrier test of surrogate spore-forming bacteria to assess sporicidal chemicals for use against Bacillus anthracis. Appl Environ Microbiol 74:676-681

Mallozzi M, Bozue J, Giorno R, Moody KS, Slack A, Cote C, Qiu D, Wang R, Mckenney P, Lai EM, Maddock JR, Friedlander A, Welkos S, Eichenberger P, Driks A (2008) Characterization of a Bacillus anthracis spore coat-surface protein that influences coat-surface morphology. FEMS Microbiol Lett 289:110-117

Mclennan SD, Peterson LA, Rose JB (2009) Comparison of point-of-use technologies for emergency disinfection of sewage-contaminated drinking Water. Appl Environ Microbiol 75:7283-7286

Oncu S, Oncu S, Sakarya S (2003) Anthrax-an overview. Med Sci Monit 9:RA276-RA283

Pinzón-Arango PA, Scholl G, Nagarajan R, Mello CM, Camesano TA (2009) Atomic force microscopy study of germination and killing of Bacillus atrophaeus spores. J Mol Recognit 22:373-379

Pinzón-Arango PA, Nagarajan R, Camesano TA (2013) Interactions of antimicrobial peptide chrysophsin-3 with Bacillus anthracis in sporulated, germinated, and vegetative states. J Phys Chem B 117:63646372

Plomp M, Leighton TJ, Wheeler KE, Malkin AJ (2005a) Architecture and high-resolution structure of Bacillus thuringiensis and Bacillus cereus spore Coat surfaces. Langmuir 21:7892-7898

Plomp M, Leighton TJ, Wheeler KE, Malkin AJ (2005b) The highresolution architecture and structural dynamics of Bacillus spores. Biophys J 88:603-608

Rosen DL (2006) Airborne bacterial endospores detected by use of an impinger containing aqueous terbium chloride. Appl Opt 45:31523157

Schenck H, Simak P, Haedicke E (1979) Structure of polyvinylpyrrolidone-iodine (povidone-iodine). J Pharm Sci 68: $1505-1509$

Setlow P (2003) Spore germination. Curr Opin Microbiol 6:550-556

Setlow P (2007) I will survive: DNA protection in bacterial spores. Trends Microbiol 15:172-180

Stoimenov PK, Klinger RL, Marchin GL, Klabunde KJ (2002) Metal oxide nanoparticles as bactericidal agents. Langmuir 18:6679-6686

Stoimenov PK, Zaikovski V, Klabunde KJ (2003) Novel halogen and interhalogen adducts of nanoscale magnesium oxide. J Am Chem Soc 125:12907-12913

Tiller JC, Liao CJ, Lewis K, Klibanov AM (2001) Designing surfaces that kill bacteria on contact. Proc Natl Acad Sci U S A 98:5981-5985

Tiller JC, Lee SB, Lewis K, Klibanov AM (2002) Polymer surfaces derivatized with poly(vinyl-N-hexylpyridinium) kill airborne and waterborne bacteria. Biotechnol Bioeng 79:465-471

Titball RW, Manchee RJ (1987) Factors affecting the germination of spores of Bacillus anthracis. J Appl Bacteriol 62:269-273

Verma S, Jain S (2012) Complexation of $\mathrm{KBr}_{3}$ with poly (ethylene glycol): efficient bromination of aromatics under solvent-less conditions. Org Chem Curr Res 1:10000105

Verma S, Jain S, Sain B (2012) A recyclable PEG-crowned potassium tribromide $\left[\left\{\mathrm{K}^{+} \mathrm{PEG}\right\} \mathrm{Br}_{3}{ }^{-}\right]$for the synthesis of tetrabromobisphenol A. Int J Ind Chem 3:1-5

Welkos SL, Cote CK, Rea KM, Gibbs PH (2004) A microtiter fluorometric assay to detect the germination of Bacillus anthracis spores and the germination inhibitory effects of antibodies. J Microbiol Methods 56:253-265

Williams ND, Russell AD (1991) The effects of some halogen-containing compounds on Bacillus subtilis endospores. J Appl Bacteriol 70: $427-436$

Young SB, Setlow P (2003) Mechanisms of killing of Bacillus subtilis spores by hypochlorite and chlorine dioxide. J Appl Microbiol 95: 54-67

Zaman MS, Goyal A, Dubey GP, Gupta PK, Chandra H, Das TK, Ganguli M, Singh Y (2005) Imaging and analysis of Bacillus anthracis spore germination. Microsc Res Tech 66:307-311 